Mauricio Ubilla Riquelme

Escuela de Periodismo

Universidad de Santiago de Chile

\title{
El discurso del Estado chileno durante el régimen de Excepción: Dictadura de Pinochet y el 18 de octubre de Piñera
}

\section{The Discourse of the Chilean State during the State of Emergency: Pinochet dictatorship and Piñera's 18 october}

\section{Resumen}

El presente artículo analiza el rol de los medios de comunicación en el desarrollo de un discurso que legitima la violencia estatal. A partir de la dictadura de Pinochet y el 18 de octubre de Piñera como momentos históricos similares, se nos presenta la violencia en su forma discursiva y el rol de los medios de comunicación como entes que justifican el estado de Excepción por medio del uso de la palabra y la construcción de un imaginario que busca anular los conflictos y la expresión popular, evitando la posibilidad de una comunicación que aporte a la construcción de una democracia pluralista.

Palabras clave: dictadura, medios de comunicación, 18 de octubre chileno, estado de Excepción

\begin{abstract}
This article analyzes the role of the media in the development of a discourse that legitimizes state violence. Starting with the Pinochet dictatorship and Piñera's October 18 as similar historical moments, we are presented with violence in its discursive form and the role of the media as entities that justify the state of Emergency through the use of the word and the construction of an imaginary that seeks to annul conflicts and popular expression, avoiding the possibility of a communication that contributes to the construction of a pluralist democracy.
\end{abstract}

Keywords: dictatorship, mass media, Chilean 2019 riots, states of emergency

La comunicación es por excelencia un fenómeno social complejo, más aún su estudio, dado que ésta no solo "abarca distintos ámbitos, sino porque su esencia misma implica correlación, interacción, interdependencia, aspectos estos que constituyen la base misma de la idea de 
complejidad" (Aguado, 2004: 15). Sin embargo, dentro de toda la amplitud y dimensiones que poliédricamente posee la comunicación, también se le puede definir como un concepto elástico, que está constantemente transitando en la ambigüedad, la polisemia y la multidimensionalidad. Esa elasticidad de la comunicación es un elemento vital que permite conectar a todos los actores de la sociedad, y a su vez, que éstos puedan converger dentro del espacio público para construir una verdadera democracia. Sin embargo, el peligro está cuando el Estado no promueve dicho diálogo.

Frente a estas aproximaciones de la comunicación, cabe preguntarse ¿la comunicación es una ideología? En tal sentido, Perniola (2006) señala que, de todas las manifestaciones de comunicación, aquella que está vinculada a la idea de progresismo democrático, es "el medio principal de las ideologías, las cuales constituyen un conjunto de opiniones y doctrinas ya preparadas, acríticamente adoptadas como sostén de la acción política" (Perniola, 2006: 15). Sin lugar a dudas, desde la creación de la Constitución de 1980 y la negociación de la clase política chilena a la transición democrática, esa doctrina no tan solo se robustece con las reformas aplicadas en 1989, sino que se valida cuando inicia el régimen democrático el 11 de marzo de 1990.

Esta ideología de la comunicación en el Estado buscará siempre una explicación de su accionar, más aún en tiempos de crisis o, en ese caso particular, dentro de un estado de excepción. Frente a esto, el mismo Perniola afirma que no estamos en el ocaso de las ideologías de los "grandes relatos", que de una u otra manera se enmarcan en la búsqueda de justificaciones ante el accionar del sistema político gobernante, como lo fue el comunismo, el liberalismo, el fascismo, entre otros (Perniola, 2006).

En relación a ello, Foucault (1996) advierte que el poder no se concibe necesariamente como una propiedad, sino que más bien como una estrategia, vale decir, que "sus efectos de dominación no pueden ser atribuidos a una "apropiación”, sino a "disposiciones, maniobras, tácticas y técnicas" (Foucault, 1996: 33). En otras palabras, el poder, más que poseerse, se ejerce, y en este sentido la comunicación que emana de ese poder - del Estado- es incuestionable para los que están subordinados a él. Esta advertencia resulta ser una tensión bastante interesante, dado que respecto del poder como estrategia también ésta podría operar a la inversa y actuar como propiedad. Sin embargo, el factor común que opera en ellas es “el poder", en este caso, de 


\section{Mauricio Ubilla Riquelme}

discernir entre un camino u otro de los señalados por Foucault (1996), vale decir, el poder en sí mismo decide transitar entre la propiedad o estrategia. En relación a ello, Perniola (2006) reafirma que la comunicación en esta dimensión y complejidad "es por ende totalitaria, en una medida mucho mayor que el totalitarismo político tradicional" (Perniola, 2006: 18) y que, en la búsqueda de legitimar su poder en el tejido social, ésta busca trascender:

"Se equivoca quien concibe la comunicación como una elección consciente de lo efímero, lo provisorio, lo momentáneo, pues ella pretender ser duradera, constante e incluso inmortal (...) La comunicación es la defensa de la old economy que se siente amenazada en su propio terreno: el de la efectividad económica y el poder". (Perniola, 2006: 31).

La comunicación es entonces, como diría Foucault (1996), "ese mecanismo que nos atraviesa, modela nuestros cuerpos y comportamientos, se mete en nuestra vida cotidiana y comparte incluso nuestras camas y hasta los sueños" (Foucault, 1996: 50-51). En relación a este planteamiento de Foucault, y volviendo al problema del estudio, durante la dictadura de Pinochet efectivamente el régimen buscó consolidar su poder a través del control de los medios de comunicación en donde, particularmente durante los estados de excepción, se acentuaba la imagen del terrorismo y de ese enemigo interno que buscaba desestabilizar el país. Claro está, no solo a través de los medios se difundió dicho temor, también se atropellaron los Derechos Humanos mediante acciones de fuerza que, en la excepcionalidad, están permitidas. Sin embargo, si bien la comunicación es totalitaria en este tipo de contextos, no quiere decir que ésta sea del todo absoluta. Foucault (1999) precisa que siempre donde hay dominación, existe resistencia, es decir, si bien se produce una especie de absolutización del poder, en donde la propia historia se convierte en el resultado de dichas relaciones de poder, dicho absoluto nunca lo consigue:

"Eso quiere decir que, en las relaciones de poder, existe necesariamente la posibilidad de resistencia, pues si no existiera tal posibilidad -de resistencia violenta, de huida, de engaño, de estrategias que inviertan la solución- no existirían en absoluto relaciones de poder" (Foucault, 1999: 405). 


\section{Mauricio Ubilla Riquelme}

Sin embargo, de no existir el poder sin resistencia ¿sería válido entender la resistencia como algo externo al poder? quizá sea el poder un determinismo histórico del cual resulta complejo escapar.

Si bien durante la dictadura de Pinochet, se evidenció, a través de las intensas jornadas de protesta desde 1983 a 1986 - una importante y significativa resistencia, si estuvo instalado el miedo y el castigo a quienes osaran públicamente a desafiar al régimen. El miedo es un fuerte mecanismo de control psicológico, y la población chilena fue bombardeada constantemente por lo que el régimen deseaba instalar, apoderándose de la realidad y cotidianidad a la que Foucault hace mención. Por lo demás, se puede aseverar que los dispositivos comunicacionales usados por la dictadura de Pinochet iniciaron en 1974, a través de la asesoría civil efectuada por el Departamento de Relaciones Humanas y Conducta Social, subordinada a la Secretaría General de Gobierno, quienes por medio del plan secreto y confidencial denominado "Preparación Psicológica de la población para contrarrestar la acción marxista”, creado por el psicólogo Hernán Tuanes ${ }^{1}$, buscaban sembrar dicho terror en los mass media de la época frente a un enemigo que estaba en guerra con la libertad y el desarrollo al que aspiraba el país y que sólo sería posible de conquistar por medio de la Junta Militar de Gobierno y su programa de refundación institucional. El mismo Foucault (1999) expone -tomando la lógica y la acción del Príncipe de Maquiavelo- "que el objetivo del ejercicio del poder es necesariamente, mantener, reforzar y proteger el "principado" (Foucault, 1999:179), entendiendo como principado el mismo Estado, en virtud de la relación de poder que este ejerce sobre sus súbditos y con el territorio. La comunicación entonces juega un rol decisivo en dicho ejercicio para velar por la integridad del gobierno.

El discurso en tiempos de crisis o en estados de excepción, como lo acontecido durante el estallido social de octubre en 2019, demostró que el lenguaje construye realidad. No es fortuito que Piñera señala constantemente en los medios de comunicación del país la existencia de un "enemigo interno, poderoso e implacable" que puso en peligro la estabilidad democrática. La construcción de ese discurso no es en absoluto casual e improvisada, dado que ello generó el

${ }^{1}$ Colaborador del régimen, quien planificó dicho programa comunicacional con la finalidad de dictar las pautas de información que fluían a los medios de comunicación de la época cuyo objetivo buscó desacreditar la imagen del gobierno de la Unidad Popular del presidente Salvador Allende, así como también la justificación de la "guerra" que asumió el país contra el denominado "marxismo internacional". Dicho documento fue publicado de forma confidencial por medio de la Secretaría General de Gobierno y el Departamento de Relaciones Humanas y Conducta Social el día 19 de noviembre de 1974. Actualmente se puede consultar en la Biblioteca del Congreso Nacional de Chile. 


\section{Mauricio Ubilla Riquelme}

temor a la población, reabriendo no tan solo antiguas heridas en el alma nacional, como lo fue el retorno de los militares fuertemente armados a las calles, sino que también se vio materializada en la violencia que los mismos agentes del Estado llevaron a cabo contra la contra la ciudadanía, en un choque de fuerzas completamente desproporcional, y cuyo resultado fue el asesinato, la tortura y lesiones físicas completamente irreparables. Ese lenguaje es la génesis de una institucionalidad cuyo núcleo es la violencia; el poder de la violencia que, como lo expone Perniola (2006), es la violencia comunicativa:

"La cultura del rendimiento tiene a veces un aspecto violento. Pero esta violencia es cualitativamente distinta de la violencia funcional entendida como medio para obtener algo que no se logra en forma pacífica: es justamente una violencia comunicativa" (Perniola, 2006: 24).

En virtud de lo anteriormente señalado, se puede asumir entonces que la violencia del poder, desde lo comunicacional, emana particularmente dentro de un contexto social y político conflictual, o bien, como señala Agamben (2001) en un Estado de excepción ${ }^{2}$, entendiendo que esta, al momento de ser implementada, no solo coarta las libertades individuales, sino que a su vez busca desarticular y desestructurar, de forma gradual, la opinión crítica de la ciudadanía y que dicha pasividad o actitud no conflictual con el poder se naturalice. Por otro lado, cabe advertir que Agamben (2001) ha de precisar que la noción de excepcionalidad busca demostrar que ella misma excede a la excepción, convirtiéndose en norma, trascendiendo la separación entre totalitarismo y democracia. En virtud de ello, la excepcionalidad para Agamben (2001) vendría a ser la racionalidad y el paradigma del gobierno moderno, vale decir, de las mismas democracias. En consecuencia, dicha racionalidad es: "en un estado de excepción que ha pasado a ser normal, la vida es la nula vida que separa en todos los ámbitos las formas de vida de su cohesión en una forma-de-vida" (Agamben, 2001:16). A lo anterior, el filósofo dirá que:

${ }^{2}$ De la distinción expuesta por el jurista alemán Carl Schmitt (1922) del texto "Teología Política", habla de Ausnahmezustand o Estado de Excepción. Agamben particularmente es bastante crítico de la visión Schimittiana. 


\section{Mauricio Ubilla Riquelme}

"Sólo podemos comunicar con otros a través de lo que en nosotros, como en los demás, ha permanecido en potencia, y toda comunicación (como había intuido Benjamin para la lengua) es sobre todo comunicación no de un común sino de una comunicabilidad" (Agamben, 2001:19).

En relación a ello, Braud (2006) señala que el Estado se impone con el monopolio legítimo del uso de la violencia. En ese sentido, ante la posibilidad el Estado se erige como una instancia central que impone un orden mantenido mediante coerción, monopolizando el ejercicio legítimo de la violencia con la finalidad de asegurar su imposición por sobre todos, a través de una legislación protectora y que visualice a la ciudadanía como sumisa a dicha premisa (Braud, 2006).

Por otro lado, para Bourdieu y Passeron (1996) el poder - que en este caso ejerce el Estadoviene a ser una entidad que aparece dentro de una relación de fuerzas simbólicas que constantemente están en enfrentamiento y tensión. En esa línea, los autores indican que:

"Todo poder de violencia simbólica, o sea, todo poder que logra imponer significados e imponerlas como legítimas disimulando las relaciones de fuerza en que se funda su propia fuerza, añade su fuerza propia, es decir, propiamente simbólica, a esas relaciones de fuerza" (Bourdieu y Passeron, 1996: 44).

Por otra parte Braud (2006) reconoce dos tipos de violencias simbólicas, siendo la primera de ellas la "depreciación identitaria", la que tiene estrecha relación a lo que señalo en los primeros párrafos, y que podría traducirse en ataques a la identidad individual o grupal de un determinado grupo ciudadano fuertemente agredido, cuyas violencias van desde el desprecio a minorías sexuales, raciales o bien por un discurso de superioridad, y más grave aún, a la negación del sufrimiento y el dolor, a lo que Braud denomina "argumentos negacionistas", muy de la mano con la percepción pública en relación al actuar del gobierno de Piñera durante el estallido social de octubre.

La segunda violencia a la que hace mención Braud (2006) es la que proviene de lo que él denomina como la "desestabilización de los puntos de referencia", que se traduce en el ataque 
sistemático y continuo a las creencias de determinados individuos o grupo social, no tomando en consideración sus demandas, cosmovisión en torno a la vida, lo político y lo social (Braud, 2006). Es así como, frente a aquellos valores que unen a la gran mayoría social -compleja y diversaque se manifiesta en las calles demandando necesidades comunes, hay quienes descalifican o buscan ofender y desconocer esa realidad o simplemente la ignoran para no generar un puente de comunicación que permita desarrollar dentro de la convergencia, un debate y diálogo genuino.

Claro está, la violencia física es mucho más visible y medible dentro de un escenario como el expuesto en este trabajo de investigación, y como bien lo menciona el mismo Braud (2006), una violencia más instrumental para el Estado, con la finalidad de mantener el orden público. Sin embargo, el objetivo para el Estado no es del todo aniquilar a ese "enemigo", sino más bien, por medio de esa violencia, corregir la orientación de ese ciudadano que momentáneamente está extraviado y requiere ser pacificado. Ante esto, Mouffe (2012) es bastante clara al decir que la democracia y lo político no pueden ser pacificados, no se debe silenciar a la ciudadanía y a los movimientos antagónicos, sino más bien invitarlos al litigio, por ende, la democracia debe ser comprendida como escenografía del conflicto. ${ }^{3}$ En esta visión de la quietud política, donde la idea de "orden" es inconmovible, la ciudadanía es la dimensión donde debe primar tal orden.

Cobra sentido la idea de pensar lo político, recuperando el carácter conflictual de Mouffe (2015). Aquí entonces toma lógica que, bajo esa quietud y orden, exista una pacificación de todo conflicto evitando así su desborde, que puede conducir al caos y a la violencia. La violencia como tal, ahora queda limitada, sólo quienes tienen el poder de ejercerla por derecho, son quienes cautelan la democracia. En tal sentido, habría que pensar la democracia, como diría Mouffe (2015), agonísticamente, vale decir, donde constantemente esté en juego el poder que emana de ella y su hegemonía a través del litigio que proviene de la misma ciudadanía. Sin embargo, pareciera ser que, tanto la clase política dirigente como los medios de comunicación masivos del país, durante el mismo estallido social de octubre de 2019, presentaron una postura criminalizadora hacia la protesta social, anulando absolutamente el carácter agonístico de las relaciones y tensiones propias de un régimen donde convergen y habitan diversas posturas, ideas

\footnotetext{
${ }^{3}$ Debe comprenderse que tanto la dictadura como los regímenes democráticos, desde 1990, buscaron anular a un "otro", siendo ese otro el cuerpo ciudadano. Por una parte, la dictadura buscó exterminar a quienes perturbaran el orden que esta deseaba establecer y por otro, los partidos políticos de la transición buscaron anularlos y pacificarlos. En otras palabras, podríamos decir silenciarlos.
} 


\section{Mauricio Ubilla Riquelme}

y problemas particulares que aquejan su existencia, es decir, aquello que en Chile se denomina como democracia.

La democracia debe ser comprendida entonces como un medio, no como un fin. Es por ello que la ciudadanía es la que debe exigir y demandar estos principios que la misma democracia dice tener: libertad, justicia e igualdad (Mouffe, 2011). Así mismo, como señala Mouffe (2012), la democracia que carece de estos tres principios no es más que una democracia jurídica, una democracia formal. En tal sentido, pareciera ser que en Chile, desde la instalación del aparato institucional en 1980 hasta nuestros días, operan dispositivos que, sobre todo en tiempos de excepción constitucional, ante el conflicto, buscan a toda costa anular esos principios y agonismo, siendo cómplices muchas veces los medios de comunicación masivos en promover y generar esa anulación.

La comunicación entonces debería ser más bien un espacio que invite a una sana convivencia cívica y no a promover mediante el terror y la violencia su validación de poder. En tal sentido, se vuelve necesario rescatar la visión de Cortina (2013) respecto a que no basta con tener un ordenamiento jurídico si no existe una ética cívica. Esa ética compromete a todos los sectores de la sociedad, incluyendo a los medios de comunicación masivos, las autoridades políticas y sus agentes. Sin embargo, parece ser que la comunicación que emana desde ese poder, es carente de esa visión global integral de un arte de comunicar que no coarte, como señala Agamben (2001), a esa construcción de una "forma-de-vida" dentro del propio tejido social. Muy por el contrario, se ha podido observar, como señala el mismo Foucault (1992), que la emergencia genera dispositivos, vale decir, que una organización que define y positiviza, establece un orden del caos -racionalización que define una práctica- y desde ese eje, toda nuestra vida se encierra en juegos de verdad, en donde siempre es posible relativizar las verdades y no reducirlas a mera falsedad (Foucault, 1992).

Sin embargo, volviendo a esa lógica del enemigo interno, queda de manifiesto que ese discurso se ha institucionalizado en el Estado de Chile, buscando difundir un mensaje que dé cuenta de la amenaza que vive la democracia y que el estado de excepción es el mecanismo de poder que promueve y comunica como verdad absoluta ese peligro institucional. En tal sentido, se puede considerar "al poder como a cualquier otro medio de comunicación, como algo que limita la gama de selecciones del otro" (Luhmann, 1995: 17) o bien las anula completamente 


\section{Mauricio Ubilla Riquelme}

desde un punto de vista jurídico. Además, estos dispositivos no son más que entes que están en una pugna frente a un enemigo que no necesariamente es físico, sino que trasciende a la materialidad. Es por ello, que como se ha manifestado más arriba, no es casual que Piñera haga uso de un término que en la dictadura era muy común para justificar los atropellos y violaciones a los Derechos Humanos. Es lo simbólico de esa imagen representativa del enemigo que amenaza la estabilidad institucional del país; una violencia política:

"la elección de arremeter contra cosas simbólicas y no contra un enemigo físico (...) confirman que estamos ante un tipo de violencia muy distinto de la violencia política. Todos estos factores aumentan la fuerza de su impacto psicológico y la tornan impermeable a cualquier mediación” (Perniola, 2006: 27).

En virtud de ello, la función del poder en la comunicación no debería quedar necesariamente expuesta a que solo moviliza al subordinado en aceptar las órdenes de un superior (Luhmann, 1995), que por lo demás, es una concepción negativa que también Foucault (1996) confronta y se ha podido evidenciar en párrafos anteriores de este artículo. La comunicación que emane del Estado en tiempos de crisis no debería, necesariamente por miedo de la violencia, generar una visión de terror a los ciudadanos que dependemos de él, sino más bien, la política de comunicación gubernamental debe garantizar "una vida política, es decir orientada según la idea de felicidad y que se aglutina en una forma-de-vida, sólo es pensable a partir de la emancipación de aquella escisión, del éxodo irrevocable de cualquier soberanía" (Agamben, 2001: 7-18).

Lo anterior, permite entender que el uso de un lenguaje basado en símbolos sumamente violentos, como el de enemigo interno, sólo alimenta el poder represivo más que el poder que alimente el ethos cívico. Sin duda, en nuestra actual institucionalidad fundada en dictadura, solo prima el ejercicio del poder -y su validación- a través de la violencia y la fuerza. Sin embargo, "la violencia no tiene otro objetivo que el de incluir al yo en la imagen del mundo. El acto violento hace entrar por la fuerza al individuo en la escena pública y trata de hacerlo permanecer el mayor tiempo posible" (Perniola, 2006: 25). En relación a este punto, Arendt (2005) advierte 


\section{Mauricio Ubilla Riquelme}

que "toda política es una lucha por el poder; el último género de poder es la violencia" (Arendt, 2005: 48).

El poder del gobernante, bajo una judicatura que lo legitima, permite sin duda ejercer el mando, a lo que Arendt (2005) denomina como el instinto innato de dominación y de una innata agresividad del animal humano, y por supuesto, los dominados quienes se resisten a la violencia física y verbal del Estado. La resistencia, la tensión, el conflicto, desencadena finalmente en una cuestión de carácter político, una "cuestión política cae en la convicción de ¿quién manda a quién? (Arendt, 2005: 60). Claro está que, en esta medición de fuerzas abismalmente desproporcionada, la violencia del Estado no es tan solo materializado y tangible en lo físico por medio de la represión y la tortura en ambos regímenes políticos en Chile, sino que también a través del lenguaje que el mismo Estado utiliza para justificar esa violencia.

El enemigo interno, fuerte e implacable de Piñera, es símbolo de esa institucionalidad que no busca resguardar las formas-de-vida, sino más bien mantenerlas anuladas y desmembradas. Esta parece ser la política comunicacional del Estado, muy particularmente en estas situaciones de excepcionalidad. Frente a ello, toman sentido las palabras de Foucault (1999) en relación a que pareciera ser que el Estado es una forma de poder completamente individualizante y totalizador, más que un poder político que destina sus esfuerzos hacia los intereses del colectivo ciudadano o comunidad (Foucault, 1999). Ese sentido de lo colectivo es lo que Nancy (1999) señala al decir: "lo que está perdido de la comunidad - la inmanencia y la intimidad de una comunión - solo está perdido en el sentido en que una perdida tal es constitutiva de la propia "comunidad" (Nancy 1999: 30). Sin embargo, en el accionar del Estado, tomando como ejemplo lo acontecido en el estallido social de octubre de 2019, es la necesidad del ejecutivo de no escuchar la voz de la ciudadanía, o más bien, silenciarla completamente, o la misma ciudadanía autosilenciarse producto del miedo en una guerra sin cuartel con un enemigo invisible.

Pareciera ser entonces que el orden de lo invisible es lo que regula la vida. El mismo Nancy (1999) expone la idea del agotamiento y dislocación de la comunidad por medio del actuar de un Estado total o totalitarismo. Lo visibilizado en ambos regímenes políticos en Chile es fiel reflejo de "la vida colectiva de la humanidad, como lo es la lucha por la supervivencia y la muerte violenta en la continuidad de la vida dentro del reino animal" (Arendt, 2005: 102). Frente a esa 


\section{Mauricio Ubilla Riquelme}

realidad se puede afirmar que Arendt (2005) postula en una noción de la política que supere dicha fatalidad.

Hoy parece ser que la tecnología de la información y la comunicación, bajo estas lógicas de poder que contribuyen al desalineamiento y desarticulación social, apuntan, como señala Agamben (2001), a un impulso que encamina a todas las naciones de la tierra hacia un único destino común que es la alienación del ser lingüístico, que a su vez, desarraiga a todo pueblo de su morada vital de la lengua:

"la época que estamos viviendo es también aquella en la que por primera vez se hace posible para los hombres hacer la experiencia de su propia esencia lingüística; no de este o aquel contenido del lenguaje, sino del lenguaje mismo, no de esta o aquella proposición verdadera, sino del hecho mismo de que se hable. La política contemporánea es este devastador experimentum linguae que en todo el planeta desarticula y vacía tradiciones y creencias, ideologías y religiones, identidad y comunidad" (Agamben, 2001: 73).

Bajo ese desalineamiento y desarticulación social planteado por Agamben (2001), resulta significativo tomar el punto de vista de Bourdieu (2006), quien dentro de esta visión, plantea la búsqueda de una razón práctica que invite a la cordura y unidad, para ello formula y expone un grupo de interesantes preguntas que, desde lo social, se deberían responder frente a escenarios políticos tan particulares como los correspondientes a esta investigación:

“El movimiento social planteó con una fuerza enorme la cuestión de la igualdad efectiva de los derechos para todos, hombres y mujeres, nacionales e inmigrantes, habitantes de las ciudades y del campo. ¿Cómo luchar por los derechos de las mujeres, cómo conquistar una igualdad política y social real?, ¿cómo defender el acceso al saber y al empleo para todos los jóvenes, cómo garantizar una escuela pública abierta a todos?, ¿cómo combatir la exclusión, cómo imponer el derecho a la vivienda y los nuevos derechos para los desempleados, los excluidos y los pobres?” (Bourdieu, 2006:23-24). 
Quizás las respuestas a estas interrogantes apunten a comprender esta visión de dominación, poder, lucha y violencia como una problemática constitutiva dentro de lo social, Para Bourdieu (2006) la conflictividad es inherente al entramado social, es más, la propia noción de violencia simbólica es una tensión constante dentro del escenario de dominación y poder, por lo que dicha noción de violencia simbólica, como lo retrata Bourdieu (2006), lleva a reflexionar respecto a dicha noción junto al plano de lo simbólico en un terreno donde necesariamente todos los actores sociales se encuentren en una relación de percepción y reconocimiento recíprocos, en otras palabras, dicha relación es un componente esencial de la realidad de dichos actores sociales que viven, actúan y convergen en el espacio público, que por lo demás, en dicho escenario social, es donde confluyen lenguajes, códigos y símbolos. Sin embargo, "las tecnocracias" como señala el propio Bourdieu (2006) buscan imponerse frecuentemente en nombre de la autoridad y generalmente lo hacen mediante la aplicación de la violencia. Ante esto, Bourdieu invita a que:

"Debemos desarrollar nuevas formas de combate para contrarrestar adecuadamente la violencia de la opresión simbólica que poco a poco se ha ido instalando en las democracias occidentales (...) La nueva demagogia se apoya principalmente en las encuestas para legitimar las medidas represivas contra los extranjeros, o las políticas culturales hostiles a la vanguardia” (Bourdieu, 2006: 49-50).

Sin embargo, parece ser que la vida colectiva es anulada dentro de la crisis institucional, la colectividad es limitada en la excepción. Precisamente, la excepcionalidad del Estado en situaciones de crisis puede implicar no solo la pausa del ritmo institucional, sino que también una interrupción de la comunicación e información que fluye de los medios hacia la ciudadanía. Sin embargo ¿cómo entender la excepción en este contexto?

Agamben (2005) manifiesta que el origen de la institución del estado de sitio, o estado de excepción tiene su origen en la Asamblea Constituyente francesa, y entró en decreto el 8 de julio de 1791, y que particularmente "distinguía entre état de paix, en el cual la autoridad militar y la autoridad civil actuaban cada una en su propia esfera, état de guerre, en el cual la autoridad civil 


\section{Mauricio Ubilla Riquelme}

debía actuar en acuerdo concertado con la autoridad militar, y état de siege” (Agamben, 2005: 29).

Resulta importante señalar que la excepción se remite a una puesta en suspenso, o bien, en términos jurídicos, la cancelación del derecho en respuesta a una situación de crítica que ponga en peligro la estabilidad política del país. Ello, en la actual Constitución Política de la República de 1980, es la figura del Presidente de la República quien está facultado para decretar simultáneamente dos o más estados de excepción ${ }^{4}$.

En virtud de lo anterior se puede aseverar entonces que la Constitución de 1980 es la que en definitiva "regula, en un párrafo especial, el necesario equilibrio que en un Estado de derecho debe existir entre las prerrogativas exorbitantes que se conceden a la autoridad en estos estados y el grado de restricción que, durante su vigencia, pueden sufrir los derechos de las personas" (Ríos, 2002: 253).

Durante la dictadura cívico-militar, luego de la entrada en vigencia de la Constitución de 1980, Pinochet promulgó en tres oportunidades el estado de excepción: bajo el denominado estado de sitio en 1983, tras las primeras jornadas de protesta nacional, en 1984 y en 1986, luego del atentado que el dictador sufrió el 7 de septiembre. En estricto rigor, según Ríos (2002), para declarar todo o parte del territorio nacional en estado de sitio, el Presidente de la República necesita que exista la situación de guerra interna o de conmoción interior y, que ante dicha situación, el congreso acuerde con el ejecutivo su aceptación. En dicho contexto, quienes cumplían el papel legislativo del país era la Junta Militar de Gobierno.

Es aquí cuando la retórica referente a un enemigo interno da pie y justificación al ejercicio en pleno de esta facultad constitucional. El mismo Pinochet, la noche del 7 de septiembre de 1986, a horas del atentado, por medio de Televisión Nacional de Chile -el único canal que tenía completa cobertura a nivel nacional y además controlado directamente por el régimen- anuncia

\footnotetext{
${ }^{4}$ Durante el año 1974 (cuatro años antes de la puesta en marcha de la Constitución de 1980), la dictadura dicta un documento oficial, denominado Acta Constitucional (A.C.) $\mathrm{N}^{\circ} 4$, dicha Acta, pese a su promulgación y debida publicación en el Diario Oficial el 13 de septiembre de 1976, nunca llegó a regir. Según el propio Ríos (2002), este oficio de Acta Constitucional fue ideada para regir durante el régimen militar y así se colige de sus términos. Por otro lado, salvo el caso de "subversión", cuya denominación fue cambiada por la más amplia y comprensiva al de "emergencia" como lo conocemos hoy en día Todo ello fue afinado más tarde en la Constitución de 1980, incluyendo la arcaica denominación original del Acta Constitucional No 4: "Regímenes de Emergencia”.
} 


\section{Mauricio Ubilla Riquelme}

que "ya está bueno que los señores políticos se den cuenta que estamos en una guerra entre el marxismo y la democracia... o el caos o la democracia",

En los sucesos ocurridos durante el estallido social de octubre, Piñera invoca el Artículo 40, número 3, en el que frente "situaciones de grave alteración del orden público, daño o peligro para la seguridad nacional el Presidente de la República con acuerdo del C.S. $\mathrm{N}^{6}$, podrá declarar todo o parte del territorio nacional en estado de emergencia” (Ríos, 2002: 259). El día domingo 20 de octubre de 2019 Piñera, por medio de una conferencia de prensa, señaló a todos los medios de comunicación; "estamos en guerra".

En virtud de lo anteriormente señalado, De Martino (1973) tomado de Agamben (2005) "las medidas excepcionales son el fruto de los períodos de crisis política y, en tanto tales, están comprendidas en el terreno político y no en el terreno jurídico-constitucional" (De Martino, 1973: 320). Sin embargo, comunicacionalmente, para el gobierno de Piñera durante el estallido social, si hay una justificación del estado de excepción que, en términos constitucionales, se denomina en esta fase Emergencia, dado que es un problema institucional que amenaza directamente según el ejecutivo- a la democracia:

"El objetivo de este Estado de Emergencia es muy simple, pero muy profundo: asegurar el orden público, asegurar la tranquilidad de los habitantes de la ciudad de Santiago, proteger los bienes tanto públicos como privados y, por sobre todo, garantizar los derechos de todos y cada uno de nuestros compatriotas que se han visto seriamente conculcados por la acción de verdaderos delincuentes que no respetan a nada ni a nadie",

Sin embargo, según Ríos (2002), pese a que en virtud de lo mandatado por la misma Constitución de 1980, los derechos relacionados con la información y el ejercicio de los medios a comunicar, serían susceptibles de afectarse en el estado de excepción constitucional en el Estado

\footnotetext{
${ }^{5}$ Noticiario 60 Minutos, “Atentado a la comitiva de su Excelencia el Presidente de la República en la ruta G5 del Cajón del Maipo". 07 de septiembre de 1986.

${ }^{6}$ Consejo de Seguridad Nacional.

${ }^{7}$ Gobierno de Chile, Prensa de la Presidencia, comunicado del 19 de octubre de 2019 "Presidente declara el Estado de Emergencia en las provincias de Santiago, Chacabuco y en las comunas de San Bernardo y Puente Alto para normalizar el orden público. Consultado el 19 de noviembre de 2020. Disponible en: https://prensa.presidencia.cl/comunicado.aspx?id=103631
} 


\section{Mauricio Ubilla Riquelme}

de Asamblea; suspender en la libertad de información y de opinión, así mismo restringir o imponer censura a la correspondencia y las comunicaciones, ello dispuesto en el Artículo 41, №10. Del mismo modo, en el Estado de Sitio, se pueden restringir las de información y opinión en virtud del Artículo $41 \mathrm{~N}^{\circ} 2$. El estado de emergencia solo limita constitucionalmente el ejercicio de la libertad de locomoción y el derecho de reunión, como indica el Artículo 41, № 4. (Ríos, 2002). Esto indica que efectivamente, el estado de emergencia según la constitución, no implica que el gobierno deba limitar o restringir las actividades informativas a la población.

Es acá donde se produce una contradicción vital si consideramos que el día 19 de Octubre de 2019, en plena gestación del movimiento social, Sebastián Piñera cita al Palacio de La Moneda a los directores ejecutivos de los canales de televisión del país, en compañía del Ministro del Interior Andrés Chadwick. Estas reuniones, que al inicio fueron programadas con celoso secretismo, fueron filtradas horas más tarde e inmediatamente denunciadas por la Federación de Trabajadores de Televisión (FETRATV), el Colegio de Periodistas de Chile, entre otras asociaciones y prensa independiente. Bajo esa mirada, el ejecutivo transmite a la ciudadanía la noción de crisis, bajo una situación de alta complejidad en donde se amenaza el orden público. Sin embargo, pareciera ser que incluso los mismos acontecimientos exceden al propio derecho. Es aquí donde se produce una tensión importante, dado que "el estado de necesidad, sobre el cual se funda la excepción, no puede tener forma jurídica, sino que la definición misma del término se hace difícil, ya que se sitúa en el límite entre la política y el derecho" (Agamben, 2005: 23). Ello es reforzado por Saint-Bonnet (2001), tomado de Agamben (2005), al señalar que el estado de excepción viene a constituir un "punto de desequilibrio entre derecho público y hecho político" (Saint-Bonnet, 2001: 28).

En consecuencia, dentro de esta pausa o cancelación del ritmo político-institucional, y en virtud de la Constitución Política de 1980, el presidente estará facultado para tomar decisiones excepcionales, aunque ello implique incluso romper con el estado de derecho. Es así como incluso el 12 de noviembre de 2019, las jornadas de protesta ciudadana llegaron a un punto máximo de presión, y en dicho momento el propio gobierno señaló que había "perdido el control 


\section{Mauricio Ubilla Riquelme}

de la calle" dicho estado de excepción ¿es una cuestión de derecho?

El término "estado de excepción” para Agamben (2005) está situado en lo que denomina "incertidumbre terminológica", a lo incierto propiamente del concepto "como término técnico para la totalidad coherente de fenómenos jurídicos que se propone definir" (Agamben, 2005: 2728).

En tal sentido, si el poder político se articula bajo la lógica de mandar y obedecer, lo esencial a ello es la eficiencia que la cabeza del Estado, el gobernante, logre conseguir comunicacionalmente, asumiendo que la eficiencia se mide de cierto modo por el grado de obediencia. Ante esto Arendt (1988) resulta ser bastante clara respecto a que "si la esencia del poder es la eficacia del mando, entonces no hay poder más grande que el que emana del cañón de un arma, y sería muy difícil decir en qué forma difiere la orden dada por un policía de la orden dada por un pistolero" (Arendt, 1988:140).

Frente a esta noción de Arendt (1988) en relación a la eficacia del mando, Foucault (1978) precisa que en gran medida el esfuerzo intelectual y teórico de Occidente ha estado orientado a establecer conexiones o puentes entre el derecho y el poder político que dirige los destinos de muchos, con la finalidad de fortalecer las posibilidades del poder en demandar a la ciudadanía obediencia, y por otra parte también, hasta donde se encuentra el límite en el que esos ciudadanos están obligados a obedecer. Pareciera ser entonces, que la democracia amenazada por el mismo tejido social que la compone y le da vida a la misma, en la excepción constituye una amenaza, que debe ser defendida por el Estado y sus instituciones armadas.

No es casual que el mismo Pinochet, el 31 de diciembre de 1973 señala públicamente que; "la democracia, que siempre hemos respetado, será custodiada por las instituciones armadas, para impedir que pueda ser violada". ${ }^{9}$ Del mismo modo, en la excepción vivida en Chile durante el estallido social de octubre de 2019, Piñera invoca la Ley de Seguridad del Estado, con la

\footnotetext{
${ }^{8}$ Diario La Tercera, 13 de noviembre de 2019 "La tensa noche en que Piñera decidió no sacar de nuevo a los militares". P. Catena, S. Minay, I. Caro y M. E. Fernández. Consultado el 19 de noviembre de 2020. Disponible en:https://www.latercera.com/la-tercera-pm/noticia/la-nerviosa-noche-pinera-decidio-no-sacar-nuevo-los-militares/899167/

${ }^{9}$ Mensaje de Pinochet a los chilenos en vísperas de la celebración de año nuevo. Dicha frase fue extraída del artículo (2017)

"Algunas observaciones sobre el uso del concepto de democracia" de Lucía Gabriela Solavagione. Rheinische FriedrichWilhelms-Universität de Bonn, Alemania.
} 


\section{Mauricio Ubilla Riquelme}

finalidad que las Fuerzas Armadas velen por la infraestructura crítica, garanticen el orden público, y sobre todo, la democracia y la institucionalidad vigente.

"hemos invocado la Ley de Seguridad del Estado a través de querellas que persiguen el objetivo de que las personas que han cometido esos gravísimos actos de delincuencia enfrenten a la justicia y asuman sus responsabilidades (...) que además no respetan los derechos ni las libertades de sus compatriotas (...) En una democracia, un estado de derecho como el que con tanto esfuerzo hemos construido todos los chilenos en nuestro país, no debe haber espacio alguno para la violencia ni la delincuencia que hemos conocido en los últimos días en nuestra ciudad" $"$.

La política ejercida por ambos gobiernos buscó instalar una comunicación que se orienta hacia la anulación de las disputas y los antagonismos, en otras palabras hacia una pasividad del conflicto. Evitar por la fuerza las posturas adversas de manera gradual, se muestran comunicacionalmente como una virtud, sin embargo dicha virtud es un mecanismo a favor del orden institucional presente. Ante esta anulación y criminalización del movimiento social, se considera a éste como un acto delictivo, cuando dicha concepción es completamente errada. En virtud de ello, Arendt (1988) también separa al desobediente civil del desobediente criminal, puesto que el primero viola la ley en «público»y no en «secreto», y «aunque disiente de la mayoría, actúa en nombre y en favor de un grupo»; por último, diferencia al desobediente civil del revolucionario, teniendo en cuenta que tal diferencia no siempre es clara (Arendt, 1988: 83).

La criminalización del movimiento social dentro del estado de excepción como fórmula de control ante la opinión pública por parte del gobierno es la forma en que busca legitimar su autoridad y poder. La Comunicación en situaciones de crisis debería entenderse como procesos dinámicos, interactivos, de intercambio de información y opinión entre los diversos actores de la sociedad, grupos e instituciones que convergen dentro del mismo territorio, sin embargo parecería ser que esas lógicas y dispositivos comunicacionales del Estado no apuntan a dicho

\footnotetext{
${ }^{10}$ Gobierno de Chile, Prensa de la Presidencia, comunicado del 19 de octubre de 2019 "Presidente declara el Estado de Emergencia en las provincias de Santiago, Chacabuco y en las comunas de San Bernardo y Puente Alto para normalizar el orden público. Consultado el 19 de noviembre de 2020. Disponible en: https://prensa.presidencia.cl/comunicado.aspx?id=103631
} 


\section{Mauricio Ubilla Riquelme}

diálogo cívico. Ante esta misma reflexión, Arendt (1988) enfatiza sobre la imperiosa necesidad de construir un modelo comunicativo orientado a la acción, en el que puedan converger y en donde el poder no habite solo en el Estado, sino en las aptitudes de los hombres que buscan actuar cohesionadamente. En otras palabras, una sinergia social, que sea capaz de establecer un consenso limpio sin dispositivos o mecanismos violentos, que se transforme significativamente en "el dominio de los hombres sobre los hombres basado en los medios de violencia legítima, es decir, supuestamente legitimada" (Arendt, 1988:138). Por supuesto legitimidada por la judicatura, y es aquí donde las palabras de Cortina toman un especial significado en virtud de que "no bastan las leyes, es preciso un compromiso ético" $" 11$ de todos los actores de la sociedad y perseguir metas comunes.

Ante esta visión de Arendt, resulta esencial tomar a Habermas en torno a lo "La legitimidad del poder que el Estado moderno monopoliza consiste en la legalidad de las decisiones, en la observancia de procedimientos jurídicos, con lo cual la legalidad acaba a la postre basándose en el poder de aquellos que pueden definir qué es lo que ha de considerarse un procedimiento legal" (Habermas, 1981: 460).

Sin embargo ¿qué papel juegan los medios de comunicación ante dicho compromiso ético? ¿responden al interés colectivo?

\footnotetext{
${ }^{11}$ Diario El País, Conferencia El País TV. Adela Cortina "La Filosofia es una forma de escuchar a los que hemos acallado". 23 de enero 2015. Consultado el 20 de noviembre de 2020. Disponible en https://elpais.com/cultura/2015/01/23/actualidad/1422014054_565558.html
} 
Mauricio Ubilla Riquelme

\section{Bibliografía}

Agamben, G. (2001). Medios sin fin: notas sobre la política. Valencia: Editorial Pre-Textos.

Agamben, G. (2005). Estado de Excepción: Homo sacer I, II. Buenos Aires: Adriana Hidalgo Editora.

Aguado, J. M. (2004). Introducción a las teorías de la comunicación y la información. Murcia: Departamento de Información y Documentación, Facultad de Comunicación y Documentación, Universidad de Murcia.

Arendt, H. (1988). La crisis de la república. Madrid: Editorial Taurus.

Arendt, H. (2005). Sobre la violencia. Madrid: Editorial Alianza.

Amnistía Internacional (2020). “Ojos sobre Chile: violencia policial y responsabilidad de mando durante el estallido social”. Informe emitido el 20 de octubre de 2020. Londres.

Bourdieu, P. \& Passeron, J. (1996). La Reproducción, Elementos para una teoría del sistema de enseñanza. Madrid: Editorial Popular.

Bourdieu, P. (2006). Pensamiento y acción. Buenos Aires: Editorial Zorzal.

Braud, P. (2006). Violencias políticas. Madrid: Editorial Alianza.

Cortina, A. (2013). ¿Para qué sirve realmente la ética? Barcelona: Editorial Paidós.

Foucault, M. (1978). Microfísica del poder. Madrid: Ediciones de la Piqueta.

Foucault, M. (1996). Vigilar y Castigar. México D.F.: Editorial Siglo XXI.

Foucault, M. (1999). Estética, ética y hermenéutica. Buenos Aires: Editorial Paidós.

Habermas, J. (1981). Historia y crítica de la opinión pública. Madrid: Editorial Gustavo Gili.

Luhmann, N. (1995). Poder. Editorial Anthropos. Barcelona, España.

Luhmann, Niklas (2007). La realidad de los medios de masas. Mexico D.F.: Universidad Iberoamericana/Anthropos. En Becerra, Gastón; Arreyes, Vanessa (2013) "Los medios de comunicación de masas y las noticias como objeto de estudio de la sociología en la perspectiva del constructivismo operativo de Niklas Luhmann”. Revista Mad, $\mathrm{N}^{\circ} 28$. Universidad de Chile [pp. 47-60]. Chile. 
Mauricio Ubilla Riquelme

Mouffe, Chantal (2011). En torno a lo político. Buenos Aires: Editorial Fondo de Cultura Económica.

Mouffe, Chantal (2012). La paradoja democrática: el peligro del consenso en la política contemporánea. Barcelona: Editorial Gedisa.

Mouffe, Chantal (2015). El retorno de lo político. Comunidad, ciudadanía, pluralismo, democracia radical. Barcelona: Editorial Paidós.

Nancy, J. (1999). La Comunidad desobrada. Madrid: Editorial Arena.

Perniola, M. (2006). Contra la comunicación. Buenos Aires: Amorrortu Editores.

Ríos, L. (2002). Los estados de excepción constitucional en Chile. Revista Ius et Praxis, v. 8, $\mathrm{n}^{\circ} 1$ [pp. 251-282]. Universidad de Talca, Chile. Disponible en https://dx.doi.org/10.4067/S071800122002000100014 